\title{
Investigation of thermo-mechanical response of a geothermal pile through a small-scale physical modelling
}

\author{
Hussein Hashemi Senejani ${ }^{l}$, Omid Ghasemi-Fare ${ }^{2, *}$, Davood Yazdani Cherati ${ }^{2}$, and Fardin Jafarzadeh ${ }^{l}$ \\ ${ }^{1}$ Department of Civil and Environmental Engineering, Sharif University of Technology, Tehran, Iran \\ ${ }^{2}$ Department of Civil and Environmental Engineering, University of Louisville, Kentucky, USA
}

\begin{abstract}
Energy piles have been used around the world to harvest geothermal energy to heat and cool residential and commercial buildings. In order to design energy geo-structures, thermo-mechanical response of the geothermal pile must be carefully understood. In this paper, a small scale physical model is designed and a series of heating thermal cycles with various vertical mechanical loads are performed. The instrumented pile is installed inside a dry sand bed. Changes in pile head displacement, shaft strains and pile and sand temperatures are monitored using an LVDT, strain gauges and thermocouples, respectively. Prolonged heating cycles, which would continue until boundary temperature changes, would allow the investigation of excessive heat injection when service loads are active on the pile. The thermal response is discussed including confirmation of a temperature influence zone around the pile, the increase in soil temperature, and minimum vertical heat dispersion in the soil. The mechanical response includes plastic settlements when the vertical load passes $20 \%$ of ultimate capacity. Plastic settlements have been observed at the half of the capacity reported for the shorter thermal cycles in similar models. The decrease in the capacity indicates a reduction in elastic response of the soil during longer thermal cycles.
\end{abstract}

\section{Introduction}

Ground source heat pumps are among the most efficient and environmentally friendly heating and cooling systems [1]. Taking advantage of the already drilled boreholes for the building's foundation, energy piles would implement GSHPs within their drilled shafts, even increasing efficiency due to the higher thermal conductivity of concrete compare to grout [2]-[4]. The number of energy piles used around the world has significantly increased in recent years [5]. Even though no failure due to thermal interactions of such deep foundations have been reported so far, the understanding of energy piles under thermomechanical loading is desired for long term applications, and optimum designs with rational conservatism[6].

Several experimental tests have been performed in literature. Laoui et al. [7], Amis et al., Borne-Webb and Amatya [6], [8], [9], performed field tests to study the thermo-mechanical (TM) behavior of energy piles. Wang et al.[10] analyzed the TM loading of model energy pile using a very small soil box. Murphy et al. and Murphy and McCartney performed centrifuge tests [4], [11], [12]. Recently $\mathrm{Ng}$ et al. conducted similar tests and analyzed [13].

Early attempts to perform small-scale tests were done by Wang et al. [14] and later by Kalantidou et al. [15] and Yavari et al. to better understand the performance of energy piles [16]. Kramer et al, and Ghasemi-Fare and Basu analyzed the TM behavior of energy piles using a fully controlled physical model test [17] [18].
In the following study, a physical model is developed, instrumented and tested under various constant mechanical service loads and various thermal cyclic loads to further investigate the performance of energy piles under cycling thermal loading through physical modelling.

\section{Experimental method}

\subsection{Model set-up}

The experimental set-up is shown in Fig. 1, and a picture of the set-up with the embedded pile is shown in Fig. 2. The model tank has dimensions of $1000 \times 1000 \times 800 \mathrm{~mm}$ (Length $\times$ width $\times$ height). The soil used in this study is dry Babolsar sand. Table 1 presents the properties of the Babolsar sand. The model pile is a closed-end aluminum tube with an external diameter (D) of $20 \mathrm{~mm}$. The pile has a $600 \mathrm{~mm}$ length, and an embedded depth of $400 \mathrm{~mm}$. The soil is evenly rained using a calibrated raining device with the target relative density of $70 \%$. The pile was fixed at the desired depth in the middle of the tank while the raining continues. This method of installation would represent the installation of non-displacement piles [19].

Table 1. Mechanical properties of Babolsar sand

\begin{tabular}{cc}
\hline Parameter & value \\
\hline Maximum Void ratio, $\mathrm{e}_{\max }$ & 0.77 \\
Maximum Void ratio, $\mathrm{e}_{\min }$ & 0.58 \\
\hline
\end{tabular}

\footnotetext{
* Corresponding author: Omid.ghasemifare@1ouisville.edu
} 


\begin{tabular}{cc}
\hline Specific Gravity, Gs & 2.81 \\
Soil Type (USGS) & SP \\
Mean particle size, D50 & $0.18 \mathrm{~mm}$ \\
\hline
\end{tabular}

Four main criteria were maintained in the tests to reduce scaling effects and boundary conditions based on previous pile tests. The ratio of the container width to pile diameter are suggested to be in the order of 8 to 20 to minimize the size effect [20]-[22]. In this study, a ratio of 50 is considered. The distance from the pile toe to the bottom of the container is 7.5 times the pile diameter, which is greater than that of suggested by Salgado in axially loaded piles [23]. To minimize the grain size scale effects, the ratio of pile diameter to $\mathrm{D}_{50}$ of the soil are suggested to be at least 50 to 100 [19], [24], which is about 111 in the current study. Also tests stopped as soon as the soil box boundary's temperature changed.

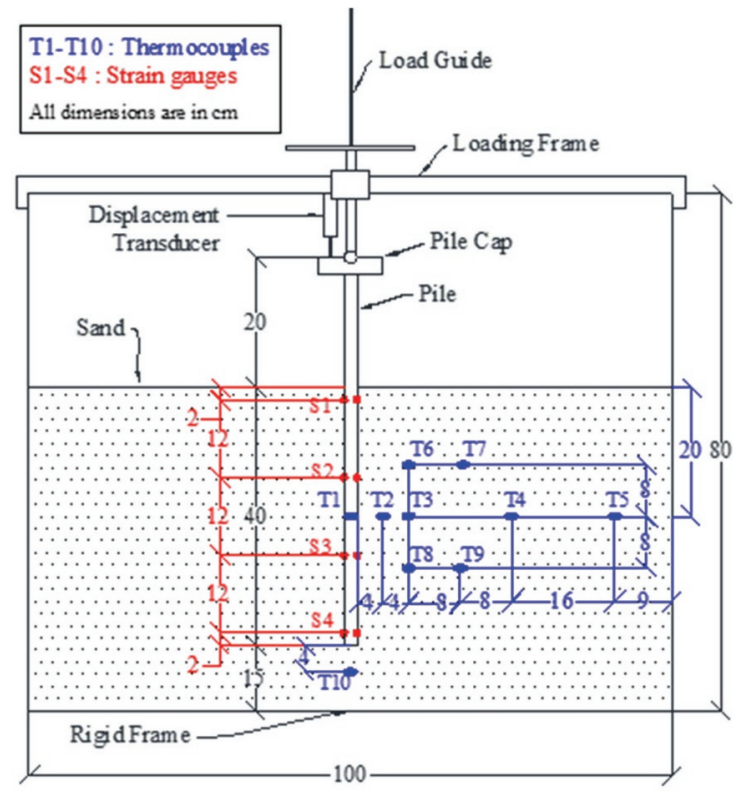

Fig. 1. The schematics of the set-up with sensors arrangements

Ten thermocouples are embedded inside the soil tank to measure soil temperature variations during thermal loading. Four strain gauges are stuck on the pile surface to measure changes in axial strain. An LVDT is used to measure the pile head displacement. A U-shaped heater element with controlled heating flux is embedded inside the pile. The pile is then filled with water to increase the heat transfer rate from heat exchanger tubes. The temperature of the pile is assumed to be homogeneous.

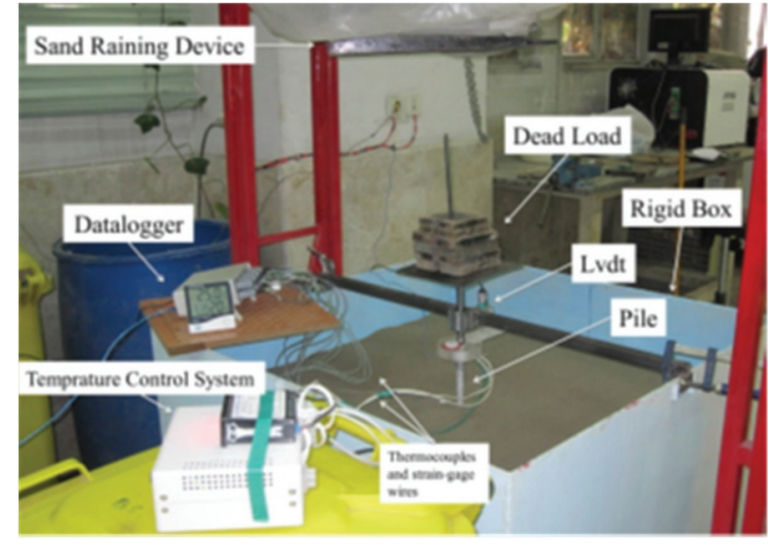

Fig. 2. Assembled set-up with the embedded pile in sand

\subsection{Procedure and test program}

The test program is shown in Fig. 3. A pile load capacity test $(\mathrm{EF})$ is conducted to determine the ultimate bearing capacity of the pile, corresponding to the settlement of $10 \%(2 \mathrm{~mm})$ of the pile diameter. Then 10 thermomechanical tests are performed (E1-E10). In each test, the pile is axially loaded to $450 \mathrm{~N}$ at $50 \mathrm{~N}$ increments, to simulate the service load condition. The axial load is then kept constant through the thermal loading tests. Then the geothermal pile is heated from $25{ }^{\circ} \mathrm{C}$ to $45{ }^{\circ} \mathrm{C}$. To minimize the heating in each test is stopped when the boundary temperature rises by $1{ }^{\circ} \mathrm{C}$. This prolonged cycle can determine the effect of cyclic thermal loading on soilpile interaction.

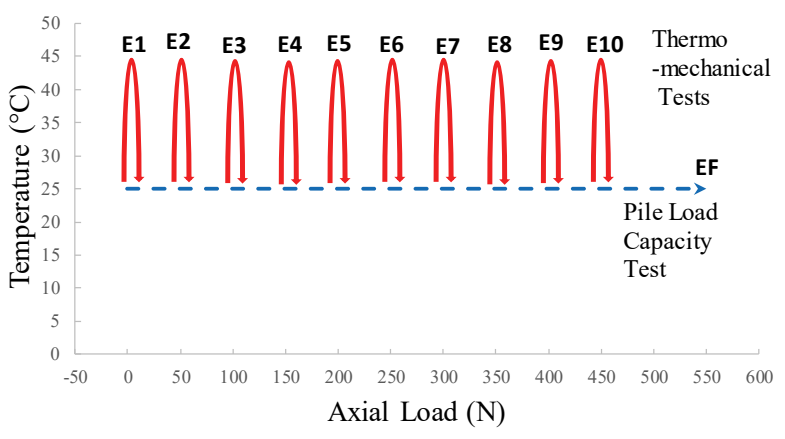

Fig. 3. The test program

\section{Experimental results and discussion}

The results of the pile load capacity test is presented in Fig. 4. The ultimate bearing capacity of the pile is estimated at $550 \mathrm{~N}$. 


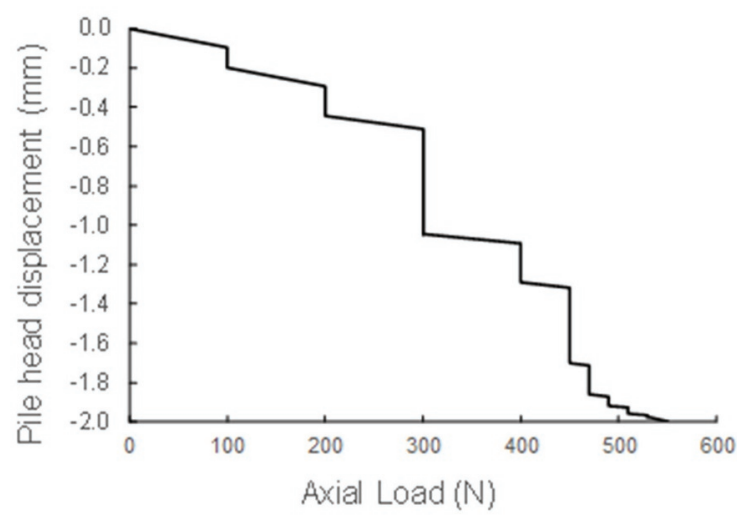

Fig. 4. Load-settlement from the pile load capacity test

The results of temperature change in the thermocouples at various times are presented in Fig. 5. In
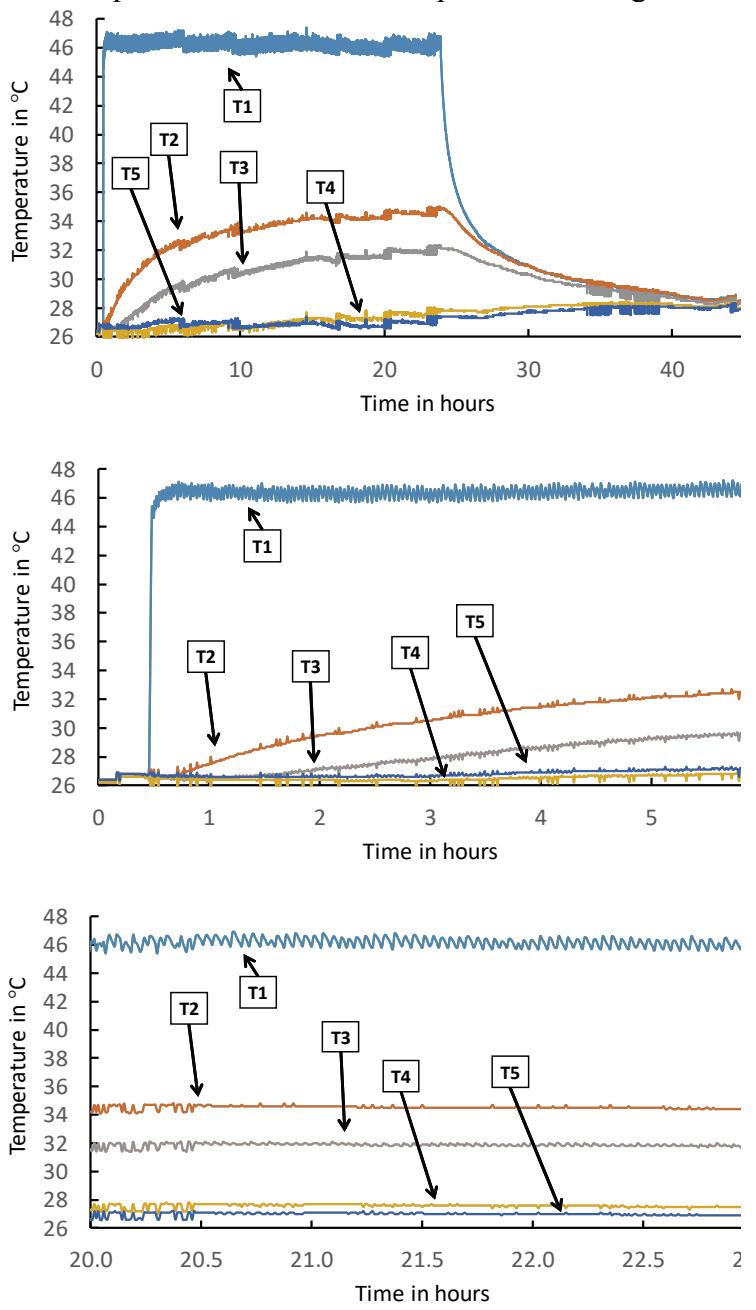

this study, the thermal results of the E2 Test is only presented due to the similarity of the thermal response throughout the soil for various conditions. In this test, after the pile is loaded to $50 \mathrm{~N}$, thermal loading is applied for 24 hours and then the heating is stopped and the soil and pile is allowed to reach thermal equilibrium.

Fig. 5 shows that soil temperature increments are equal at T10, T0, and T7. Please Note, T9 and T7 are 4 times further from the pile compared to T10. Comparison of soil temperatures at T7, T9, and T10 confirm that heat transfer surrounding an energy pile is a radial phenomenon, as reported in literature [16][25]. An influence zone of $2 \mathrm{D}(4 \mathrm{~cm})$ from the pile can be recognized which faces higher thermal gradient at the initial heating and relaxation period. Although smaller influence zones have been reported by Wang et al. [26], the research in literature showed that the influence zone can be varied if the heating phase is prolonged [25].
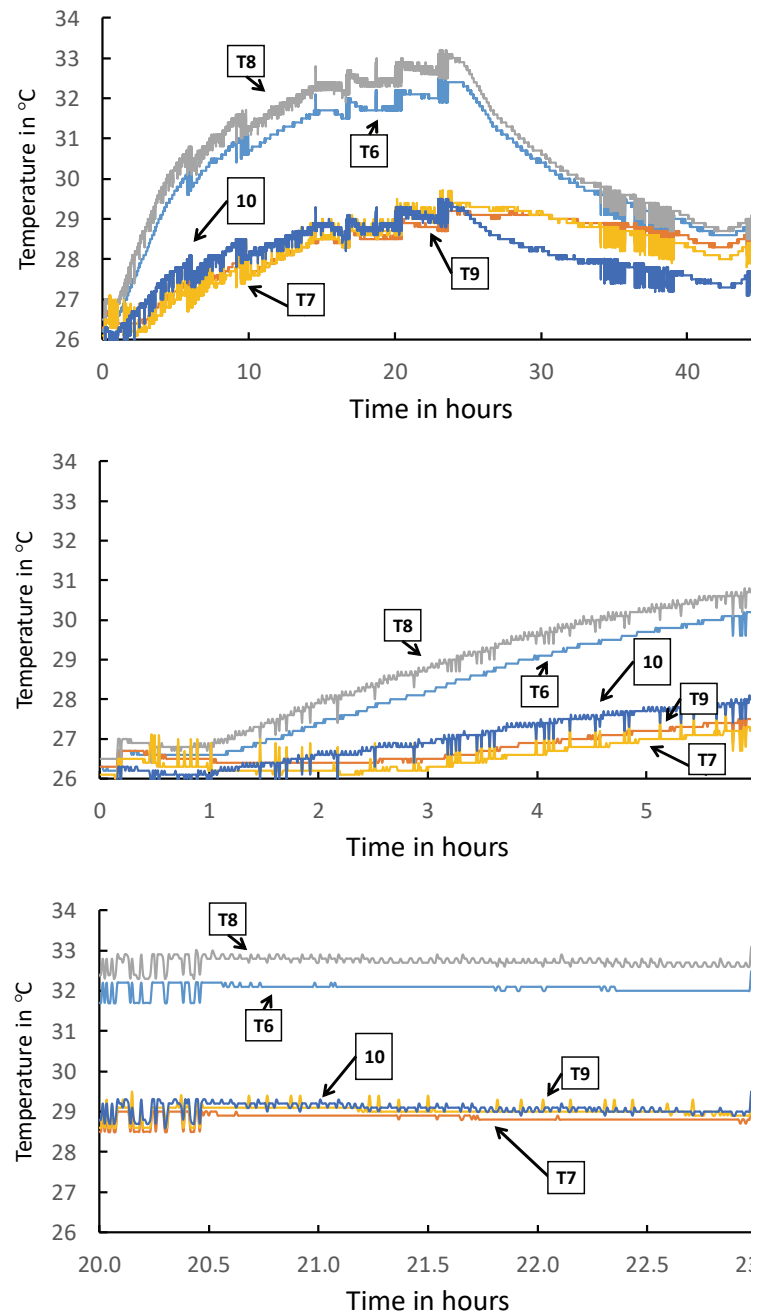

Fig. 5. Temperature variations in thermocouples T1-T10 at various times throughout the E2 test 
As shown in Fig. 5, when a constant heat flow is reached, T2 and T3 have an increase in temperature of 10 ${ }^{\circ} \mathrm{C}$ and $6{ }^{\circ} \mathrm{C}(50 \%$ and $30 \%$ of the pile temperature increase), respectively. For T4 and T5 with distances of more than $12 \mathrm{D}$, the temperature change is less than $2{ }^{\circ} \mathrm{C}$ $(10 \%)$ and can be neglected. It can also be noted that soil temperature at $2 \mathrm{D}$ starts to change after 15 minutes while it took more than an hour soils at 4D distance from the pile. This shows the immediate temperature changes at the influence zone of 2D. Thermocouples with similar distances from the pile have experienced similar thermal changes throughout the test, with the slight higher temperature changes for the deeper sensors which can be due to the boundary conditions on the soil surface, allowing heat loss through heat convective flow from the soil surface. The effect of insulated and non-insulated boundary conditions at the ground surface has been discussed in literature [27]. Although the influence zone of $2 \mathrm{D}$ is reported for the radial heat transfer surrounding the energy pile, the temperature changes from $2 \mathrm{D}$ distance vertically under the pile toe has changed less than $15 \%$ of the pile temperature increase.

The temperature contours of the test is presented in Fig. 6. It can be also seen in this figure that soil temperature evolution is happing and the soil temperature after one day of heating and one day of relaxation period increase by an average of $1.5^{\circ} \mathrm{C}$ inside the soil box.

The pile head displacements along with pile temperature for Tests with 0,50 and $150 \mathrm{~N}$ loads are shown in Fig. 7. The pile head heaves as the heating starts for the smaller mechanical load on the pile. While,
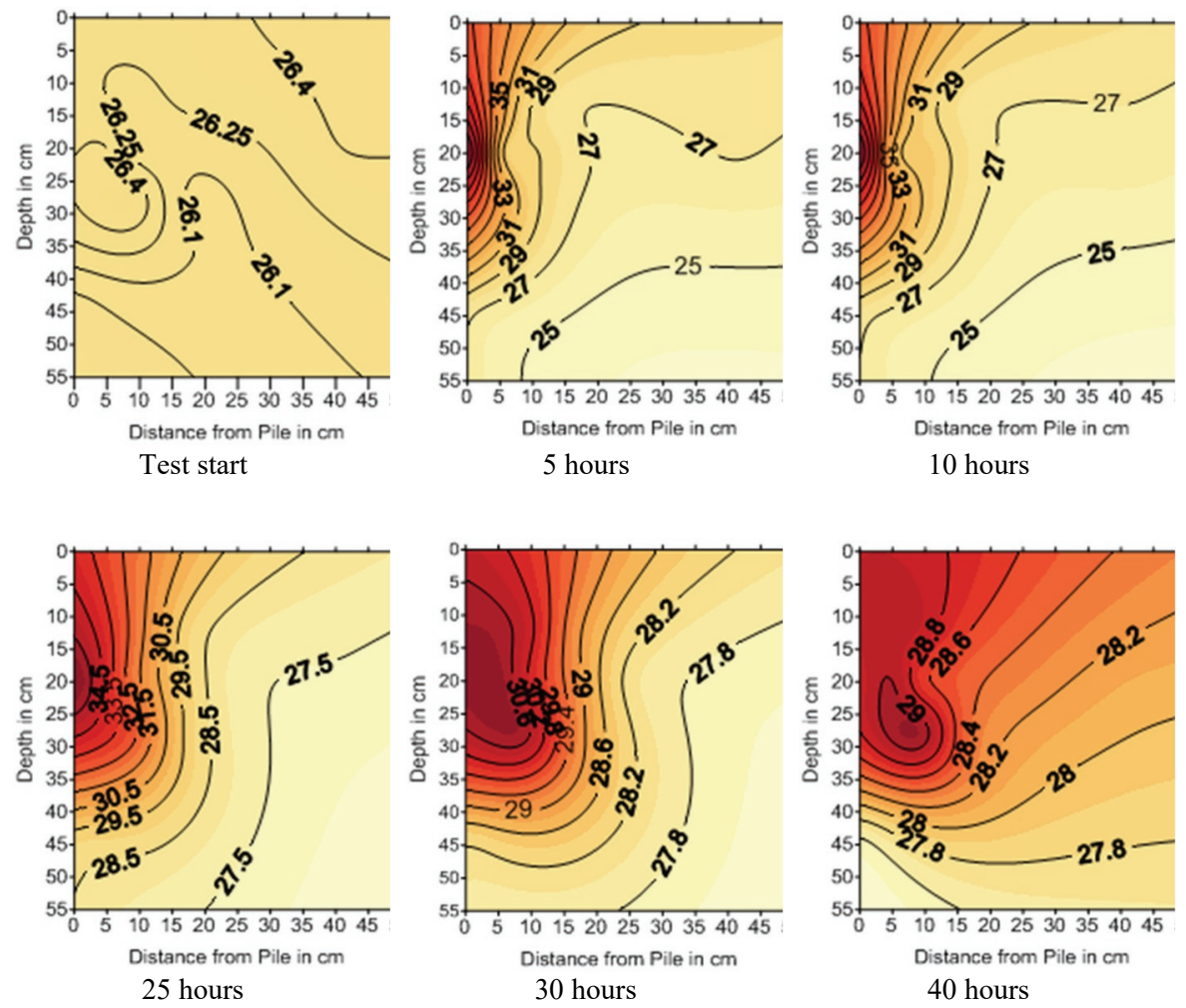

Fig. 6. Temperature contours for test E2 around the pile

downward displacement at the pile head is expected for the cooling loading. These displacements may recover after the relaxation period when the heating-cooling pump is turned off. However, some residual heave is recorded in this study at the end of the test. The larger residual heave recorded for the test with no mechanical loading, is because of the free head condition. When the service load increases and a critical percentage of the ultimate load capacity of the pile is approached, which in this study is estimated at $20 \%$ of ultimate capacity $(100 \mathrm{~N})$, the residual heave becomes negligible indicating a thermoelastic response in the pile. The settlement in this phase is caused by the pile expansion downwards and is elastic as the pile retracts to its initial conditions. However, for larger mechanical loads, residual non-elastic settlements are recorded which mainly is due to the mechanical loading and the pile head restrain. The three distinct responses of heave, elastic and settlement can also be seen in the pile head displacement versus pile temperature diagrams shown in Fig. 8. The induced heave and settlements recorded are observed to be heavily affected by the pile head restrain as the heating would expand the pile, making it heave when the head is free, and cause the pile to undergo settlements when the head is restrained with loads. It should be noted that the expansion of soil grains could also contribute to the small residual heave in the free condition as it would also affect the pile settlement during tests with high pile loads.

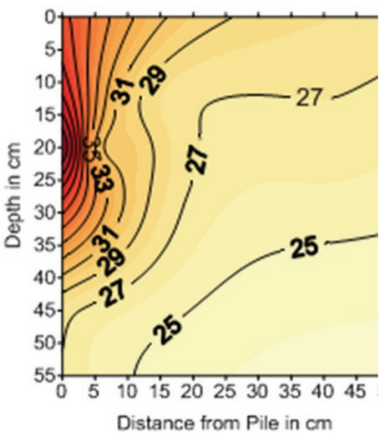

10 hours
46 hours, end of test
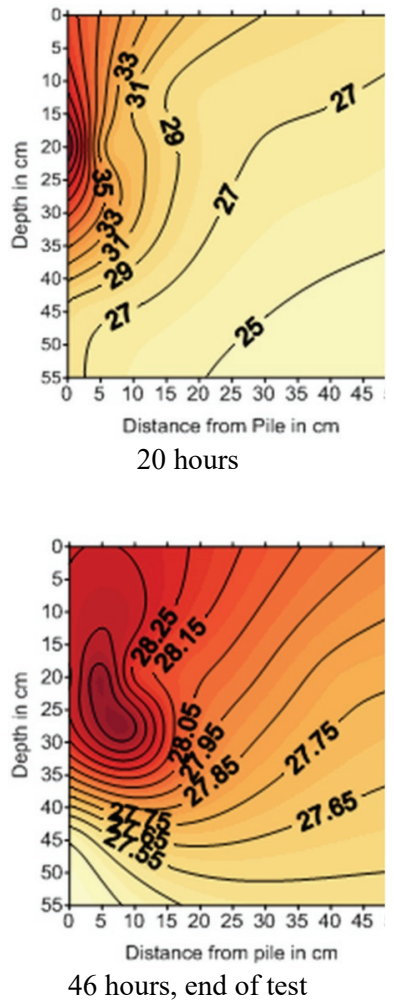

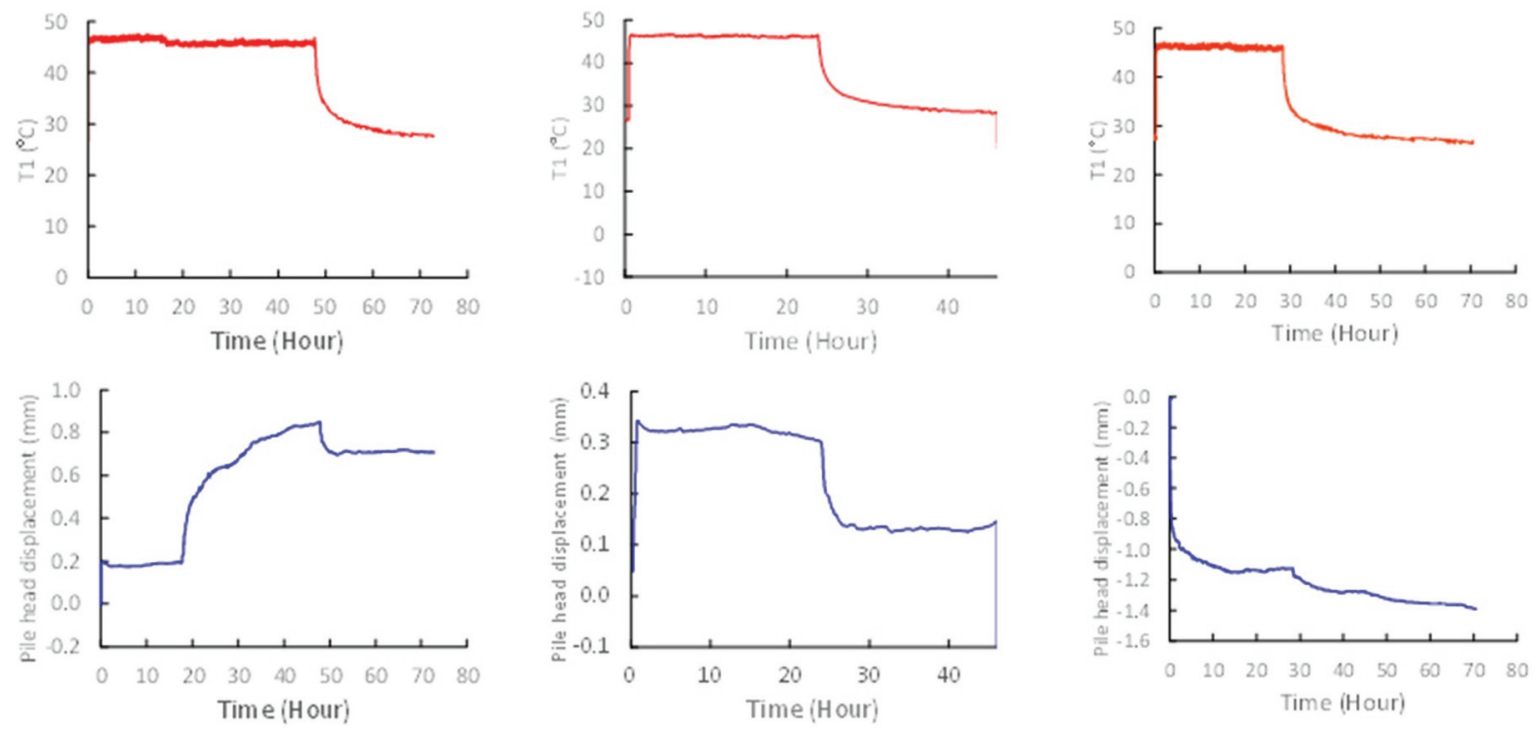

$0 \mathrm{~N}$ pile load

$50 \mathrm{~N}$ pile load

$150 \mathrm{~N}$ pile load

Fig. 7. Pile head displacement under tests with 0,50 and $150 \mathrm{~N}$ service loads

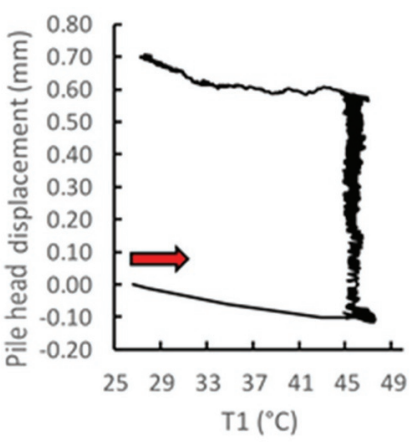

$0 \mathrm{~N}$ pile load

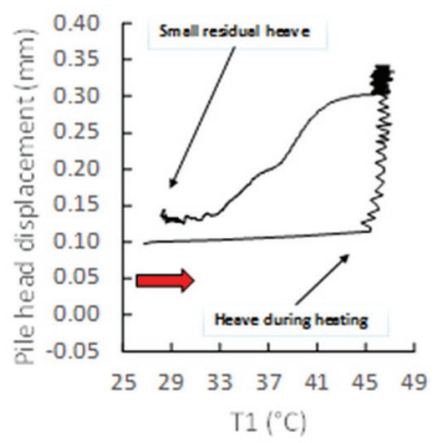

$50 \mathrm{~N}$ pile load

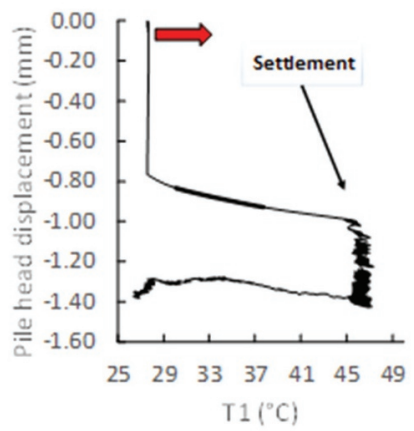

$150 \mathrm{~N}$ pile load

Fig. 8. Pile head displacement versus pile temperature under tests with 0,50 and $150 \mathrm{~N}$ service loads

Since irreversible settlements are observed when the mechanical load exceeds $20 \%$ of the ultimate load capacity of the pile, a higher safety factor must be implemented for the foundation design. Of course the detrimental effects of large number of cycles and lengthened exposure to heat must also be studied through fatigue and creep behavior, respectively. The critical percentage of ultimate load capacity has been previously reported at $30 \%$ and $40 \%$ previously in similar setups testing on dry sand [15][16]. This observed decrease in capacity of the pile could be attributed to the longer thermal cycles.

\section{Conclusions}

In the current study, a small-scale physical model of energy pile is tested under constant service loads undergoing heating thermal cycles. The model consists of an aluminum pile embedded in dry sand. Thermocouples, LVDT and strain gages are embedded in the soil tank to monitor the TM performance of the energy pile. The following conclusions can be made from this study:
- Heat in the soil is mostly transferred radially around the pile.

- An influence zone of 2D from the pile is recognized which undergo immediate changes in temperature with higher thermal gradient compared to farther zones (at least $50 \%$ of the pile temperature increase).

- Temperature changes in the soil for distances of more than 12 pile diameters are less than $10 \%$ of pile temperature increase and can be neglected.

- Temperature changes at 2D under pile toe are less than $15 \%$ of pile temperature increase, indicating small temperature changes under the pile.

- Residual temperature increase of $1.5^{\circ} \mathrm{C}$ is observed after one day of heating and one day of cooling. This implies that to reach to initial soil temperature longer relaxation period is needed.

- The pile would heave under thermal loads in dry sand with no mechanical loading.

- The pile shows elastic response in thermal loads when the service load is approximately $20 \%$ of the pile ultimate capacity called critical percentage. 
- Plastic settlements would appear when the service loads exceeds the $20 \%$ of the ultimate pile capacity.

It must be mentioned that more tests with wider range of both mechanical and thermal capabilities should be performed to better understand the thermo-mechanical performance of energy piles. Further studies are needed to investigate fatigue, creep and the residual thermal effects of the energy geo-structures.

\section{References}

[1] M. L'Ecuyer, C. Zoi, and J. S. Hoffman, Space conditioning: the next frontier: the potential of advanced residential space conditioning technologies for reducing pollution and saving consumers money. Office of Air and Radiation, US Environmental Protection Agency, 1993.

[2] T. Mimouni, "Thermomechanical characterization of energy geostructures with emphasis on energy piles," EPFL, 2014.

[3] L. Laloui and A. Di Donna, "Understanding the behaviour of energy geo-structures," Proceedings of the Institution of Civil Engineers, vol. 164, no. 4, p. 184, 2011.

[4] J. S. McCartney, M. Sánchez, and I. Tomac, "Energy geotechnics: Advances in subsurface energy recovery, storage, exchange, and waste management," Computers and Geotechnics, vol. 75, pp. 244-256, 2016.

[5] H. Brandl, "Energy foundations and other thermoactive ground structures," Géotechnique, vol. 56, no. 2, pp. 81-122, 2006.

[6] B. L. Amatya, K. Soga, P. J. Bourne-Webb, T. Amis, and L. Laloui, "Thermo-mechanical behaviour of energy piles," Géotechnique, vol. 62, no. 6, p. $503,2012$.

[7] L. Laloui, M. Nuth, and L. Vulliet, "Experimental and numerical investigations of the behaviour of a heat exchanger pile," International Journal for Numerical and Analytical Methods in Geomechanics, vol. 30, no. 8, pp. 763-781, 2006.

[8] P. J. Bourne-Webb, B. Amatya, K. Soga, T. Amis, C. Davidson, and P. Payne, "Energy pile test at Lambeth College, London: geotechnical and thermodynamic aspects of pile response to heat cycles," Géotechnique, vol. 59, no. 3, pp. 237-248, 2009.

[9] T. Amis, P. Bourne-Webb, C. Davidson, B. Amatya, and K. Soga, "The effects of heating and cooling energy piles under working load at Lambeth College, UK," presented at the DFI Conference New York, 2008.

[10] B. Wang et al., "Field and laboratory investigation of a heat exchanger pile," in GeoCongress 2012: State of the Art and Practice in Geotechnical Engineering, 2012, pp. 4396-4405.

[11] K. D. Murphy, J. S. McCartney, and K. H. Henry, "Thermo-mechanical response tests on energy foundations with different heat exchanger configurations," Acta Geotechnica, vol. 1, p. 17, 2014.

[12] K. D. Murphy and J. S. McCartney, "Seasonal response of energy foundations during building operation," Geotechnical and Geological Engineering, vol. 33, no. 2, pp. 343-356, 2015.

[13] C. W. W. Ng, C. Shi, A. Gunawan, and L. Laloui, "Centrifuge modelling of energy piles subjected to heating and cooling cycles in clay," Géotechnique Letters, vol. 4, no. 4, pp. 310-316, 2014.

[14] B. Wang, A. Bouazza, and C. Haberfield, "Preliminary observations from laboratory scale model geothermal pile subjected to thermalmechanical loading," in Geo-Frontiers 2011: Advances in Geotechnical Engineering, 2011, pp. 430-439.

[15] A. Kalantidou, A. M. Tang, J.-M. Pereira, and G. Hassen, "Preliminary study on the mechanical behaviour of heat exchanger pile in physical model," Géotechnique, vol. 62, no. 11, p. 1047, 2012.

[16] N. Yavari, A. M. Tang, J.-M. Pereira, and G. Hassen, "Experimental study on the mechanical behaviour of a heat exchanger pile using physical modelling," Acta Geotechnica, vol. 9, no. 3, pp. 385-398, 2014.

[17] C. A. Kramer, "An experimental investigation on performance of a model geothermal pile in sand," 2013.

[18] O. Ghasemi-Fare and P. Basu, "A practical heat transfer model for geothermal piles," Energy and Buildings, vol. 66, pp. 470-479, 2013.

[19] V. Fioravante, "On the shaft friction modelling of non-displacement piles in sand," Soils and foundations, vol. 42, no. 2, pp. 23-33, 2002.

[20] F. Schnaid and G. T. Houlsby, "Assessment of chamber size effects in the calibration of in situ tests in sand," Géotechnique, vol. 41, no. 3, pp. 437-445, 1991.

[21] A. K. Parkin and T. Lunne, "Boundary effects in the laboratory calibration of a cone penetrometer for sand," Norwegian Geotechnical institute publication, no. 138, 1982.

[22] L. M. Kraft Jr, "Performance of axially loaded pipe piles in sand," Journal of Geotechnical Engineering, vol. 117, no. 2, pp. 272-296, 1991.

[23] R. Salgado, The engineering of foundations, vol. 888. McGraw-Hill New York, 2008.

[24] D. Loukidis and R. Salgado, "Analysis of the shaft resistance of nondisplacement piles in sand," Géotechnique, 2008.

[25] C. A. Kramer, O. Ghasemi-Fare, and P. Basu, "Laboratory thermal performance tests on a model heat exchanger pile in sand," Geotechnical and Geological Engineering, vol. 33, no. 2, pp. 253271, 2015.

[26] C. Wang, H. Liu, G. Kong, C. W. Ng, and D. Wu, "Model tests of energy piles with and without a vertical load," Environmental Geotechnics, vol. 3, no. 4, pp. 203-213, 2016.

[27] O. Ghasemi-Fare and P. Basu, "Influences of ground saturation and thermal boundary condition on energy harvesting using geothermal piles," Energy and Buildings, vol. 165, pp. 340-351, 2018. 